\title{
REFLEXÕES SOBRE O NÃO DITO NA EDUCAÇÃO MUSICAL: UM ESPAÇO A SER OCUPADO PELA MÚSICA CONTEMPORÂNEA
}

Érica Dias Gomes ${ }^{1}$

\section{Resumo}

A educação musical formal no Brasil tem privilegiado o repertório do período de prática comum, em detrimento de composições de outros contextos. Este trabalho visa refletir sobre esta predominância, questionando a ausência específica da produção contemporânea no ensino formal. Foi realizada revisão teórica, abordando relações entre a história da educação musical brasileira e a consolidação deste tipo de repertório, além de alguns apontamentos sobre produções musicais contemporâneas e características da contemporaneidade. Desta forma, aponta-se para a importância da presença da música erudita contemporânea enquanto possibilidade de articular a necessidade de ampliação de repertório com o desenvolvimento da musicalidade em um aspecto mais amplo, a partir das relações entre as múltiplas tendências estéticas na construção musical.

Palavras-chave: Música Contemporânea; Educação e Cultura; Ensino de Música; Música e Formação

\section{HERANÇAS CULTURAIS E EDUCAÇÃO}

A educação musical no Brasil, em todos os segmentos do ensino formal, carrega fortes relações com uma visão tradicional de ensino, que pressupõe uma valorização exacerbada de determinados conteúdos, em detrimento da ampla gama de possibilidades que existe na história da música. Atualmente, existem cursos isolados que representam uma nova abertura, no sentido de proporcionar ensino de diferentes tipos de música. Porém, ainda predomina uma

\footnotetext{
${ }^{1}$ Professora assistente de música na Universidade Estadual do Centro-OEste do Paraná (UNICENTRO). Endereço: Rua Abílio Carvalho Bastos, 1368 Rio Bonito Irati - PR, Brasil. Telefone: 42 99575047. E-mail: ericaunicentro@gmail.com
} 
GOMES, Érica Dias,

visão elitista, na qual percebemos uma cristalização na forma de seleção do repertório - ou até mesmo a reprodução pura deste - que define as "boas músicas" para este ensino. Há necessidade de se pensar a respeito dos fatores que levaram a esta hierarquia entre tipos de músicas, e que contribuem também para uma postura radical e até preconceituosa diante da diversidade de manifestações musicais existentes.

A história deste ensino no Brasil mostra que foram privilegiadas concepções do conhecimento baseadas em parâmetros estabelecidos pela classe dominante, ignorando a realidade cultural e musical contemporânea. Os vestígios deste tipo de dominação persistem, sendo o repertório um elemento que pode representar a resistência a transformações disseminada por esta visão de ensino. A tendência liberal tradicional predominante na história da educação no país permanece forte, preparando o estudante para os papéis da sociedade de acordo com aptidões individuais. Entre outras características que podem ser percebidas, podemos ressaltar o caráter homogeneizador, que não leva em consideração as diferenças sociais e culturais dos alunos. Os conteúdos priorizados por esta visão de educação são aqueles conhecimentos e valores sociais acumulados pelas gerações adultas e repassados ao aluno como verdades absolutas (LIBÂNEO, 1990). Assim, percebemos que esta visão legitima e cristaliza saberes considerados importantes pelos detentores do poder, o que no Brasil foi concretizado na idealização da cultura europeia como modelo para a construção de uma ideia de ensino musical. As características deste ensino podem ser percebidas na atualidade, mesmo que de forma transformada, como, por exemplo, deslocamento do ideal para outras culturas, de países "desenvolvidos", apesar das recentes crises pelas quais passaram e/ou passam, como a cultura norte-americana.

Pensando especificamente nos tipos de música veiculados pela mídia, podemos perceber certos referenciais presentes em gêneros frequentemente explorados. É comum que brasileiros associem música com o gênero canção que se caracteriza, primordialmente, pela relação entre melodia cantada e letra. De acordo com Moraes (2000), entre outros gêneros, a canção popular é o mais presente em diferentes experiências humanas, principalmente nos setores menos escolarizados, e contém forte poder de comunicação, sobretudo no meio urbano, sendo representante da realidade social. Dessa forma, ao analisarmos a música popular, podemos destacar a canção que, segundo Costa (2003), é gênero híbrido que se caracteriza pela conexão entre a materialidade verbal (letra) e a materialidade musical (melodia), dimensões inseparáveis nesse gênero. Além disso, geralmente se trata de 
manifestação popular, diferindo da erudita por ser sintética e compacta, e também por não seguir rigorosamente normas estruturais vinculadas a um método composicional específico ou a sistemas de notação (COSTA, 2003). Segundo Ulhôa (1997), a canção tem origem no contato entre as culturas luso-europeia e ameríndia, por meio do canto, e da união entre melodia e letra. Assim, a melodia teria se tornado o elemento formal gerador da canção brasileira, seja na sua forma solo ou acompanhada.

Além desta característica de interdependência entre letra e melodia, o gênero canção, usualmente conhecido, é construído na lógica do sistema tonal, consistindo em uma melodia acompanhada, com existência, geralmente, de refrão, repetição geralmente explorada como fator que identifica a música. Ao analisarmos conceitos relacionados à música, como melodia, harmonia e o próprio termo música, em diferentes meios - desde enciclopédias virtuais baseadas na ideia de construção aberta e coletiva até livros comumente utilizados para o ensino básico de teoria musical - verificamos esta visão predominante de música enquanto construção tonal e, por vezes, até mesmo relacionadas à ideia de canção, especificamente (GOMES; CUNHA, 2012).

Ao longo da história da música ocidental, podemos dizer que existem pontos que remetem esta construção musical com construções de determinados períodos. Considerando o tonalismo, construção que foi surgindo, de certa maneira, paralelamente à construção do pensamento moderno, podemos dizer que:

Esse tipo de sistema resultante do pensamento musical europeu, consolidado a partir do século XVII, teve máxima expressão no período de prática comum (common practice period), e desempenhou papel determinante para a cultura musical ocidental como um todo [...]. (GOMES; CUNHA, p. 35)

O classicismo (1750-1810) é o estilo que representa o apogeu do tonalismo, apresentando como características, entre outras, o culto à forma e à simetria, a predominância da melodia acompanhada enquanto estrutura textural, a linearidade, a clareza na apresentação, desenvolvimento e conclusão, a presença de um tema claro na melodia, o tempo métrico regular. Desta forma, pode-se estabelecer o paralelo da lógica composicional da canção com os padrões do período clássico.

Pensando nesta lógica tonal como referência direta que possuímos de música, e também nas ideias que atribuímos a atividades musicais que podem ser percebidas ao vermos a trajetória do ensino de música no país, podemos dizer que, no ensino, esta relação se dá de 
forma a priorizar determinadas práticas musicais, consideradas superiores no senso-comum, por estarem veiculadas à ideia de status e de poder. Assim, embora o pensamento sobre educação musical na escola tenha se modificado aos poucos, nas últimas décadas, ainda podemos verificar que a música erudita é tida como repertório modelo, especialmente aquela ligada ao tonalismo que se estruturou na Europa após a Idade Média até o fim do século XIX.

Pensar em um ensino de música na escola voltado somente para este tipo de música, além de limitador, é contraditório, se pensarmos no hibridismo cultural que no país se deu, sendo que, como ressalta Souza (2007), o Brasil tem na diversidade base para suas culturas.

Keith Swanwick (1993) mostra que também na Inglaterra é comum ver conteúdos musicais cristalizados em função de uma perspectiva de educação que não dialoga com a contemporaneidade. Dentro desta visão, o autor compara o professor de música tradicional com uma "caixa postal", a filtrar as boas correspondências (conteúdos) para os alunos que, no caso, também se concentra no estudo da música do período de prática comum. Muitas vezes, quando é feita uma imposição deste conteúdo sem contextualização e sem relacionar com produções contemporâneas, os alunos não conseguem encontrar correspondência entre a música "da escola" com a que estão acostumados a escutar, o que implica, em geral, em um desinteresse destes pelo ensino.

\section{A TRAJETÓRIA DO ENSINO DA MÚSICA E A ESCOLHA DE REPERTÓRIO}

Pode-se dizer que o padrão estético-musical ocidental, de maneira geral, se baseia no sistema tonal, que foi cristalizado e teve o ápice durante o período de prática comum (commom practice period), que engloba a música erudita europeia do estilo barroco até o começo do século XX. Para exemplificar a forma com que foi se consolidando esta situação no ensino de música do Brasil, podemos pontuar alguns períodos importantes na história: período colonial; vinda da corte portuguesa; e acontecimentos ao longo do século XX. Entre estes acontecimentos, destacamos: a primeira geração dos Métodos Ativos em educação musical; o nacionalismo; Koellreutter e o grupo Músiva Viva; e a segunda geração dos Métodos Ativos.

No período colonial, os jesuítas tiveram forte influência na educação como um todo, estabelecendo um rigor metodológico no ensino e impondo padrões da cultura lusitana, em detrimento da local. A influência para a música podia ser vista nos cantos de trabalho em 
meio a ações cotidianas, nos acalantos e cantigas ibéricos e nas orações e hinos católicos traduzidos para o tupi, além da grande influência da música portuguesa nas músicas ligadas ao Estado e à Igreja (FONTERRADA, 2008). Segundo Budasz (2006), as principais influências estavam na música ibérica, francesa e italiana.

Neste período, a educação musical já acontecia, embora de forma diferenciada. Para as elites, a música era muito importante como forma de instrução dos jovens, na tentativa de reprodução da cultura musical europeia, o que indicava e reforçava a condição social. Para estes, a música era supérflua, no sentido de não servir para uma profissionalização ou conhecimento aprofundado, e sim para garantia de status, de condição para a "civilidade", em contraposição aos escravos e aos nativos indígenas, considerados "primitivos". Por outro lado, o ofício de músico era atribuído a pessoas de baixa classe social, que passavam por processo de aprendizagem vinculado à Igreja, com os denominados mestres de capela, ou por incentivo e patrocínio dos senhores de engenho, que mantinham músicos escravos para demonstração de poder (BUDASZ, 2006; MARIZ, 2005). Desta forma, podemos perceber como este período foi determinante não só para a educação musical, como também para a consolidação na sociedade brasileira de uma concepção de música, do papel do músico e também da criação de uma hierarquia entre os diferentes tipos de música, baseadas no padrão europeu. Estes padrões influenciaram também na interpretação hierárquica da importância e do papel dos instrumentos musicais, e no distanciamento entre música erudita e religiosa da música popular, presente nas manifestações culturais locais. Ainda hoje, esta influência pode ser percebida em comportamentos e ideias presentes na sociedade, como a existência de estereótipos ligados a instrumentistas, e a segregação segundo visão hierárquica da música.

Com a vinda da família real portuguesa, houve um grande incentivo para a arte, com destaque para as artes visuais e a música, representada, principalmente, pela Missão Artística Francesa (FONTERRADA, 2008; ARSLAN; IAVELBERG, 2006). Segundo Ferraz e Fusari (2009), outros fatos importantes foram a criação da Escola Real das ciências, Artes e Ofícios do Rio de Janeiro (depois transformada na Imperial Academia e Escola de Belas-Artes), e de conservatórios e de teatros. Nestes espaços, percebia-se a disseminação dos padrões culturais artísticos vigentes na Europa, sendo que o ensino era baseado em orientações de instituições europeias, com destaque para as francesas. Assim sendo, estes padrões, trazidos em função da corte portuguesa, foram rapidamente assimilados por quem nela se espelhava para obter um modelo de civilização, de requinte, associados à classe dominante, e representada na figura da 
nobreza de Portugal, na mesma medida que o afastamento dos valores, das ideias, dos hábitos atrelados à vida "primitiva" do país colonizado reforçava esta imagem.

Ao longo do século XX, aconteceram diversos momentos importantes para a educação musical, trazendo influências que permitiram certos avanços, enquanto outros consolidaram alguns aspectos antes vigentes. Este trabalho não pretende aprofundar as questões históricas mais abrangentes no que tange ao ensino de música, e, desta forma, foi estabelecido um recorte, trazendo pontos relevantes com relação ao repertório utilizado nas aulas. Entre estes, destacamos: a primeira geração dos Métodos Ativos em educação musical; o nacionalismo; Koellreutter e o grupo Músiva Viva; e a segunda geração dos Métodos Ativos.

Os (posteriormente) denominados Métodos Ativos, surgidos no início do século XX, formaram diferentes núcleos (na Europa e no Japão) que influenciaram mundialmente o ensino de música, tendo consistido em diferentes abordagens desenvolvidas por educadores musicais do início do século, sendo que os precursores foram: Émile-Jaques Dalcroze, Zoltán Kodály, Carl Orff, Edgar Willems e Shinichi Suzuki. Esta primeira geração, que reúne ideias diferenciadas daquelas da educação tradicional, teve grande impacto no país, servindo de base para educadores brasileiros, como Sá Pereira e Gazzi de Sá.

Em relação ao tipo de música enfatizada nas diferentes abordagens, podemos destacar Willems que, conforme Fonterrada (2008), se posicionava contra a abordagem exclusiva no período de prática comum, defendendo a importância de desenvolver a audição em prol da aceitação de outros sistemas, o que demonstra também uma preocupação em desnaturalizar a ideia do sistema tonal, tido como padrão vigente ocidental. Desta forma, o músico buscava respaldo nas tendências musicais de sua época, que exploravam as alturas de forma diferenciada, como o microtonalismo, com uso das subdivisões do tom, e a música concreta, que explorava qualquer som enquanto som musical, com a incorporação do ruído (PAZ, 2000). Outro aspecto que teve grande impacto na educação foi a valorização da música folclórica de cada país, bem como de canções tradicionais infantis, parlendas e brincadeiras que envolvam aspectos musicais. Estas ideias vieram embasadas pelas abordagens, principalmente, de Orff e de Kodály, o que fugia do padrão antes estabelecido, trazendo a importância da apropriação do universo sonoro infantil, que envolve também uma questão cultural, em função da diversidade no repertório regional dentro do Brasil. Entre os nomes brasileiros, podemos destacar Gazzi de Sá, que procurou, em seu método, verificar 
particularidades das acentuações do idioma para o ensino de ritmo, bem como a utilização de músicas brasileiras.

A partir desta consideração sobre a música brasileira estabelecemos uma relação com um movimento importante e que ocorreu simultaneamente no Brasil, de forma a reforçar a música folclórica brasileira: o nacionalismo do início do século XX. A figura que melhor representa esta influência para a educação foi Villa-Lobos, com a implementação do seu Canto Orfeônico nas escolas, durante a Era Vargas (PAZ, 2000; MARIZ, 2005). É interessante observar a forte ligação entre o pensamento vigente na época, com ênfase na busca de uma identidade nacional, em diversos âmbitos da sociedade brasileira. Dentro das diferentes intenções e ideias por trás deste ideal, existia este forte caráter nacionalista, por exemplo, representados: pela geração nacionalista na produção musical, com destaque para Villa-Lobos na primeira geração; pelo nacionalismo na arte, de forma geral, sobre o qual se destaca também o acontecimento da Semana de Arte Moderna, impregnado também por estes anseios; pelo governo brasileiro, na figura de Getúlio Vargas, que colocou Villa-Lobos como representante do ensino musical nas escolas, com ênfase no repertório folclórico e postura fortemente cívica nas escolas.

Hans-Joachim Koellreutter também representou forte influência na educação, embora seja notável sua contribuição para a composição no país. Como líder do grupo Música Viva, entre outros aspectos, apontava para a necessidade de se trabalhar, na formação musical, com a música da época, em vez de se prender somente ao repertório consagrado no passado. $\mathrm{O}$ compositor não sistematizou um método de ensino, porém, atuou de forma marcante enquanto educador em diversas cidades do país, tendo influenciado inúmeros músicos, compositores, educadores brasileiros, que das ideias musicais e pedagógicas dele se apropriaram. Koellreutter trouxe para o Brasil o dodecafonismo, além de defender uma postura diferenciada no ensino da música, em diálogo com as novas tendências que procuravam quebrar com a rigidez e as limitações do ensino tradicional (FONTERRADA, 2008; PAZ, 2000; MARIZ, 2005; CUNHA; GOMES, 2012).

Outros educadores importantes no âmbito internacional vieram na segunda metade do século XX, formando a denominada segunda geração dos Métodos Ativos, com destaque para Murray Schafer e John Paynter, que defendem fortemente a ligação do repertório utilizado com a música produzida na atualidade. Desta forma, percebemos uma valorização crescente do uso de técnicas e de materiais da música contemporânea. Schafer tem sido uma referência 
GOMES, Érica Dias,

para o ensino de música na atualidade por representar bem a relação com a realidade contemporânea: a utilização de recursos tecnológicos para captação e para edição de músicas feitas a partir de paisagens sonoras; discussão dos efeitos da poluição e da anestesia existente nos centros urbanos, com valorização da ecologia sonora; articulação do ensino de música com outras áreas artísticas, que vem fortalecer uma tendência trazida pela arte contemporânea; e a ênfase na escuta do entorno sonoro, bem como na criação (SCHAFER, 1991).

A partir desta trajetória, pode-se perceber a construção de um ideal musical baseado numa tentativa de reprodução da cultura musical europeia, e que, gradualmente, está sendo modificado, graças a novos pensamentos surgidos em todo o mundo acerca da valorização da diversidade musical.

\section{DIVERSIDADE E EDUCAÇÃO MUSICAL CONTEMPORÂNEA}

Atualmente, podemos verificar heranças desta trajetória do ensino musical em ideias e comportamentos acerca deste conhecimento. A partir da análise de alguns destes, aponta-se para a importância de se ampliar o conhecimento musical por meio da diversidade de repertório.

Com relação à hierarquia existente em relação aos instrumentos $-\mathrm{e}$, portanto, aos instrumentistas - podemos citar alguns estereótipos encontrados. Instrumentos mais raros e caros, assim como os considerados mais "difíceis", ou ainda os historicamente ligados à elite, são valorizados (piano, harpa, contrabaixo, violino) em detrimento de instrumentos encontrados mais facilmente e de maior acesso (violão, metais, flauta doce) ou ligados diretamente a manifestações populares brasileiras (cavaquinho, percussão diversa como triângulo, tamborim, pandeiro, tambores em geral, acordeon).

Existe também uma postura de preconceito acerca de músicas ligadas ao gosto popular, inclusive no ambiente de ensino, que pode ser observada tanto em professores como também em alunos de música, seja em escolas de ensino especializado ou dentro de instituições de nível superior. O preconceito aparece de diferentes formas, sendo que podemos destacar o desprezo por gêneros como funk, sertanejo universitário e pagode, por estes constituírem forma "inferior" de composição pela facilidade do processo composicional. Independente das questões referentes à lógica comercial vinculada a estes tipos de música, 
não se pode desprezar, na educação, o impacto que estas têm sobre a maior parte da sociedade. Sendo assim, há de se aproveitar características deste repertório para utilização em sala de aula - mesmo que não na prática, mas pelo menos na discussão e na reflexão - na intenção de ampliar os horizontes musicais. Ampliação de repertório não pode ser confundida com imposição de repertório, em que o professor rejeita qualquer diálogo acerca de outro tipo de música que não considere o ideal para o ensino. Quanto aos alunos, pode-se dizer que, principalmente em instituições mais tradicionais de formação superior, muitos também desprezam a música ligada à mídia, o que pode colaborar para um isolamento e uma rejeição de debates que dialogam com a sociedade como um todo, fechando-se em grupos de interesse comum, o que limita a reflexão acerca do seu próprio papel na sociedade enquanto músico.

Segundo Souza (2007), existem estereótipos sobre a música brasileira relacionados à ideia de que todo brasileiro tem uma musicalidade nata, em parte atribuída à mistura étnica, assim como à ideia de que há uma hierarquia que coloca a música europeia sobre a africana e indígena no país. Sabe-se que, onde há troca cultural, elementos diversos se misturam, originando um novo fenômeno cultural e, devido a estas trocas, a autora coloca não só o Brasil, mas a América Latina, enquanto fundamentalmente híbridos musicalmente, coexistindo várias formas de pensar e de fazer música.

Em meio a esta diversidade, focar em poucos referenciais não procederia. A questão da necessidade de se abrir o horizonte musical do aluno - ponto praticamente unânime atualmente entre educadores musicais e pesquisadores - reflete uma valorização desta diversidade, que tem ligação direta com os valores da contemporaneidade, visto que, pela diluição das fronteiras tempo e espaço, é possível entrar em contato com diferentes culturas, delas absorvendo influências e tomando empréstimos. As múltiplas trocas e empréstimos são reflexos da diminuição da relação tempo-espaço, colaborando para a diversidade, e o consumismo crescente a partir do último século reforça a ideia de autenticidade, de velocidade, e de descarte presentes nestas apropriações (LIPOVETSKY; SERROY, 2011). Também a produção científica voltada para educação musical no Brasil tem valorizado bastante esta diversidade, com o crescimento da etnomusicologia e também com a influência destes educadores do século XX. A valorização da diversidade pode ser observada pelas características da arte contemporânea, em geral, que tende à não-rejeição de influências, permitindo fusões, colagens, empréstimos, apropriações. 
Questões sobre diversidade cultural têm sido tema em diversos campos de atuação, o que colabora para o discurso acadêmico que reforça bem a necessidade de conectar os saberes dos alunos, permitindo maior articulação entre sua realidade e ampliação do repertório musical. Este é um grande desafio para o professor, tendo em vista a presença praticamente exclusiva da música midiática na escuta musical das crianças e dos adolescentes. O desafio se encontra em partir desta escuta para sua ampliação, que pode seguir para diferentes caminhos: desde a música popular em geral, até a música folclórica; as manifestações artísticas regionais; as músicas do mundo, representadas na multiplicidade de manifestações artísticas pelo mundo em diferentes contextos históricos; a música oriental (tão deixada de lado na história do ensino); além da música erudita como um todo. É uma gama infinita de possibilidades que, certamente, torna impossível o trabalho de forma a contemplar a totalidade, embora o professor deva ter a consciência de que, quanto mais diversificado seu conhecimento de repertório, maior as chances dos alunos compreenderem o discurso musical dentro de muitas possibilidades, e não só fechado em um único padrão estético.

Apenas considerando a música erudita, excetuando-se o período de prática comum, temos grandes possibilidades de trabalhar músicas que diferem da estética tonal. Podemos citar a música modal, presente tanto na Antiguidade Clássica como na cultura oriental, até a música europeia medieval e as manifestações atuais do modalismo. O período desde o final da Idade Média, passando pela Renascença até o Barroco, que contemplam a passagem do modalismo até a consolidação do tonalismo, que tem relações diretas com as mudanças de paradigmas que a consolidação do sistema capitalista trouxe em múltiplos aspectos.

Porém, entre todas estas possibilidades, somente em relação à música erudita, apontamos principalmente para a produção contemporânea, devido à sua significativa ausência na educação formal, inclusive nos cursos de formação docente. Além disto, o aspecto de que, a partir da compreensão da música produzida hoje, o aluno pode estabelecer relações mais ricas com músicas de outros contextos, tendo em vista a relação desta com os valores e as ideias que circulam na atualidade. E a partir da conexão desta música com outras, o aluno pode ampliar suas referências, que colaboram para que possa, segundo Martins et al (1998, p. 140), ver e aceitar “[...] outras perspectivas, outros modos de pensar e fazer”. O autor também defende a importância das referências serem múltiplas, podendo até serem contraditórias, pois, assim, “[...] podem provocar um rearranjo no pensar, não só artisticamente" (MARTINS et al., 1998, p. 140). 
Assim sendo, a música erudita contemporânea, enquanto absorvedora de diversas tendências em vertentes que se opõem, que se dialogam, que se complementam, em relação umas a outras e também a músicas de outras épocas, pode ser potencialmente instigadora deste olhar para a diversidade, dando ferramentas aos alunos para compreensão de diferentes formas de construção musical.

\section{MÚSICA ERUDITA CONTEMPORÂNEA E EDUCAÇÃO}

Na educação musical formal, é comum a ênfase na análise minuciosa e na técnica isolada que fragmenta o fenômeno musical, afastando, assim, da relação com o discurso musical como um todo, nas suas relações com a realidade enquanto construção simbólica. Para compreender melhor esta construção, deve-se buscar o desenvolvimento da sensibilidade às diferentes formas de produzir padrões responsáveis por criar um sentido musical. Ao tomar alguns exemplos de música contemporânea (que fogem do padrão conhecido) enquanto referência, muitos músicos encontram resistência, por não conseguir perceber estas formas de organização, em função da sua formação ter sido centrada quase exclusivamente no padrão estético do período de prática comum.

De uma forma geral, a música contemporânea é reservada principalmente à formação de compositores, e bem distante da formação de docentes. Desta forma, podemos compreender a insegurança e a desconfiança na percepção dos professores de música em relação a estas possibilidades, muitas vezes distantes de seu referencial. Este estranhamento perante o novo representa um questionamento acerca do próprio conhecimento musical, porém, caso vencido o preconceito e o receio perante este fato, a busca pela compreensão deste mundo musical pode contribuir muito para a prática docente. Desta forma, apresentaremos algumas relações entre as produções contemporâneas e aspectos do cotidiano dos alunos que permitem a defesa de sua presença na educação.

Assim como a música, a cultura contemporânea não é estática nem universal, mas sim múltipla e contraditória e baseada em trocas e influências entre grupos diversos e, desta forma, dentro da escola, é necessário refletir sobre o contexto daqueles indivíduos que lá se inserem, com toda esta complexidade presente nas relações sociais estabelecidas. Compreender os alunos para além das suas representações no interior da escola é um desafio, tendo em vista esta heterogeneidade (GUSMÃO, 2000). 
GOMES, Érica Dias,

Desta forma, é preciso admitir a limitação que este olhar recortado perante o aluno traz, embora seja importante o papel do educador enquanto mediador destes múltiplos mundos. Também é importante que a escola aja como agente transformador:

[...] promovendo o conhecimento mútuo entre diferentes, formando professores e quadros teóricos, entre muitos outros pontos. Emergem, desta perspectiva, diferentes propostas educativas baseadas em princípios democráticos e legítimos. (GUSMÃO, 2000, p. 24).

Ao mesmo tempo em que percebemos estas construções dadas pelas trocas múltiplas, vemos também a força que a mídia possui na formação dos alunos, inclusive no que se refere, por exemplo, ao consumo de modismos na música. A música midiática está presente na escuta dos alunos, sendo que não podemos ignorar este mundo enorme, a princípio exterior à escola, enquanto possibilidade de construção social e discursiva. Esta relação entre escolarização e mídia deve ser levada em consideração, devido ao poder desta última enquanto "aparelho ideológico de estado", segundo Green e Bigum (SILVA, 1995). Neste ponto, a música representa um forte instrumento de poder perante os jovens, sendo que, em meio às infinitas possibilidades de acesso a diferentes culturas musicais proporcionadas pela internet, a tendência a se ficar preso ao modismo explorado pela mídia é grande. Assim sendo, o papel do educador em apresentar novos mundos musicais é fundamental.

Mattos (1958) aponta a importância de se desenvolver a capacidade de apreensão de conteúdos relacionados à música, desde os elementos que a constituem - conhecimento relacionado à percepção da mente de superfície - até o seu superior sentido estético, englobando as relações implícitas ali existentes - conhecimentos relacionados à percepção da mente profunda. Podemos considerar que a compreensão do discurso musical requer sensibilidade, relativa à percepção imediata, e abstração, para rememorar e reconstruir a experiência sonora, em sua complexidade, o que está ligado não só à memória, mas à experiência presente da percepção também, porém, englobando uma visão total, com todas as relações entre os aspectos constituintes. Em relação à percepção imediata, a musicalidade trabalharia principalmente com os conceitos mais específicos, relativos à mente de superfície. Quando estamos estabelecendo relações mais complexas entre estes conceitos, observando as conexões implícitas, estaríamos trabalhando a abstração, no plano da mente profunda, que permite maior articulação entre conceitos. Assim, com este movimento constante e articulação entre conceitos mais e menos abrangentes, entre todo e partes, se daria a apreensão de sentido. 
Considerando que a música contemporânea, de forma geral, apresenta novas configurações, técnicas e materiais, em comparação com a música do período de prática comum, e também em relação ao modalismo da Idade Média, por exemplo, podemos perceber sua importância enquanto expansão dos conceitos, da compreensão de novas possibilidades da linguagem musical.

A importância do conhecimento de repertório na educação musical está vinculada a experiências múltiplas, não devendo o professor se fixar em determinado tipo de música. A memória musical é desenvolvida a partir do momento que o discurso musical for mais compreendido, assim como sua escuta interior. Kuhn (1988) dá ênfase também ao aspecto emocional do aluno, que influencia diretamente na sua capacidade de concentração e atenção, fatores que podem afetar sua percepção. Por isso, é imprescindível despertar no aluno a curiosidade pelo novo, instigando-o a querer conhecer e tentar compreender, em vez de rejeitar essa diversidade disponível. A arte contemporânea, de forma geral, reflete esta diversidade, esta multiplicidade de escolhas, esta convivência simultânea de diversas tendências e pensamentos, a negação da negação, e o convite à diluição entre as fronteiras.

Assim, a educação deveria despertar o indivíduo, a partir de vivências, para a reflexão sobre as significações que permeiam suas relações sociais, e sobre os valores e as ideias vigentes no seu contexto cultural, e também destes em relação a outros contextos. Desta forma, desenvolveria uma capacidade crítica para compreender e selecionar os sentidos, podendo construir, a partir do existente, e das múltiplas referências, um sentido que norteie sua ação enquanto indivíduo (DUARTE JR, 2010).

A música é uma das expressões fundamentais da cultura humana, sendo que raramente alguém fica indiferente à música. A experiência musical constitui experiência emocional socialmente compartilhada, sendo que é multifacetada no que diz respeito, além do estilo, aos modos de vivenciá-la (GALVÃO, 2006). Esses modos são influenciados por diversos fatores, e podem interferir na abertura ou não do indivíduo para músicas não pertencentes ao seu repertório usual, nas preferências musicais, na compreensão de aspectos culturais, na vivência social. Desta forma, a educação musical que busca ampliar horizontes de escuta colabora para maior compreensão do cidadão em relação ao seu meio cultural, e, consequentemente, a outros meios.

\section{CONSIDERAÇÕES FINAIS}


Pode-se dizer que uma característica que tem se fortalecido no pensamento da atualidade consiste na valorização da diversidade e, neste contexto, podemos incluir também a música. A partir desta premissa, e considerando que a ampliação do repertório é ponto comum nas abordagens pedagógico-musicais, podemos refletir sobre a importância de conectar saberes do cotidiano e preocupações atuais por meio da inserção da música contemporânea na educação musical.

Através da trajetória da educação musical no Brasil, pode-se perceber a formação de um ideal de boa música, com referência na cultura musical europeia. Perante esta influência na formação de discursos acerca da aprendizagem musical, aponta-se para a necessidade de se ampliar o conhecimento musical por meio da diversidade de repertório.

Entre as infinitas possibilidades de repertório a ser utilizado, podemos destacar a música erudita contemporânea, enquanto absorvedora de diversas tendências que utilizam processos composicionais múltiplos. Assim, pode ser utilizada abrindo caminhos para a diversidade, ao disponibilizar aos alunos uma ampla gama de construção musical.

A partir de todas estas ponderações, podemos dizer que na educação musical é preciso instigar o aluno a este contato com o novo, que pode até permitir a ampliação de seu gosto musical, desenvolvendo, assim, visão crítica em relação às diferentes produções. Ao diluir as fronteiras entre estas possibilidades e tentar compreender essa diversidade disponível, a música contemporânea pode ser essencial no sentido de possibilitar a vivência de diversas influências para a construção musical, ampliando assim as chances de despertar o aluno para a reflexão sobre as significações que permeiam suas relações sociais, e sobre os valores e ideias vigentes no seu contexto cultural, e também destes em relação a outros contextos.

\title{
REFLECTIONS ON THE REPERTORY IN MUSIC EDUCATION: FILLING THE GAP WITH CONTEMPORARY MUSIC
}

\begin{abstract}
Formal musical education in Brasil has been focusing common practice period repertory on all education segments. This research aims to reflect about this gap on musical education's repertory, especially regarding contemporary music. Therefore, theoretical review was carried
\end{abstract}


out in order to present some facts on music education's history that have contributed to this repertory consolidation. Finally some notes about both contemporary music and life are exposed as argument for the importance of discussing these relations at school. Lastly this paper defends contemporary music as a significant issue for the purpose of develops musicality and relates students' everyday life to music education.

Keywords: Contemporary Music; Education and Culture; Music Education; Music and Formation

\section{REFLEXIONES SOBRE EL REPERTORIO EN LA EDUCACIÓN MUSICAL: LA IMPORTÁNCIA DE LAS MÚSICAS CONTEMPORÁNEAS}

\section{Resumen}

En la educación musical formal en Brasil ha predominado el repertorio del periodo de práctica común, en detrimento de composiciones de otros contextos. Esta investigación tiene como propósito la reflexión sobre este predominio de la música europea, con foco en la ausencia de producciones contemporáneas eruditas en la educación musical. Fue desarrolladla una investigación bibliográfica sobre el camino recorrido por Brasil durante la consolidación del tipo de música en la enseñanza. Razones para trabajar con repertorio musical contemporáneo en educación musical son presentadas por sus aportaciones para pensar el conocimiento cotidiano.

Palabras clave: Música Contemporánea; Educación y Cultura; Educación Musical; Música y Formación

\section{REFERÊNCIAS}

ARSLAN, L. M.; IAVELBERG, R.. Ensino de arte. 1 ed. São Paulo: Thomson Learning, 2006.

BUDASZ, Rogério. Música e sociedade no Brasil colonial. Disponível em: http://dc.itamaraty.gov.br/imagens-e-textos/revista-textos-do-brasil/portugues/revista12mat2.pdf. Acesso em: 14 mar. 2014. 
COSTA, Nelson Barros da. Canção popular e ensino da língua materna: o gênero canção nos Parâmetros Curriculares de Língua Portuguesa. Linguagem em (dis)curso. Tubarão: UNISUL, v. $4, \quad$ n. $1, \quad 2003 . \quad$ Disponível em: http://www.portaldeperiodicos.unisul.br/index.php/Linguagem_Discurso/article/view/253/26. Acesso em: 01 jun. 2013.

COSTA, Rogério Luiz Moraes. Apontamentos sobre o estudo da harmonia: por uma abordagem abrangente. In: Congresso da ANPPOM, 15, 2005, Rio de Janeiro. Anais. Rio de Janeiro: UFRJ, 2005. p. 318-326.

CUNHA, Daiane Solange Stoeberl da; GOMES, Érica Dias Gomes. Música na escola? Reflexões e possibilidades. 1 ed. Guarapuava: UNICENTRO. 2012

DUARTE JR, João Francisco. A montanha e o vídeo game: escritos sobre educação. 1 ed. Campinas: Papirus, 2010.

FERRAZ, Maria Heloísa Corrêa de Toledo; FUSARI, Maria Felisminda de Rezende. Metodologia do ensino de arte: fundamentos e proposições. 2 ed. rev. e ampl. São Paulo: Cortez, 2009.

FONTERRADA, Marisa Trench de Oliveira. De tramas e fios: um ensaio sobre música e educação. 2 ed. São Paulo: UNESP; Rio de Janeiro: FUNARTE, 2008.

GALVÃO, Afonso. Cognição, emoção e expertise musical. Psicologia: Teoria e Pesquisa. Brasília: UnB, v. 22, n.2, 2006. Disponível em: http://www.scielo.br/pdf/ptp/v22n2/a06v22n2.pdf. Acesso em: 14 mar. 2014.

GOMES, Érica Dias; CUNHA, Daiane Solange Stoeberl da. Música e transformação: por um olhar diferenciado na história da música. Guarapuava: UNICENTRO. 2012.

GUSMÃO, Neusa Maria Mendes. Desafios da diversidade na escola. Revista Mediações. Londrina: UEL, v. 5, n. 2, 2000. Disponível em: http://www.uel.br/revistas/uel/index.php/mediacoes/article/view/9158. Acesso em: $21 \mathrm{mar}$. 2014.

KÜHN, Clemens. La formación musical del oído. 1 ed. Barcelona, Espanha: Editorial Labor, 1988.

LIBÂNEO, José Carlos. Tendências pedagógicas na prática escolar. In: Democratização da escola pública: a pedagogia crítico-social dos conteúdos. 9 ed. São Paulo: Loyola, 1990.

LIPOVETSKY, Gilles; SERROY, Jean. A cultura-mundo: resposta a uma sociedade desorientada. Tradução de Maria Lúcia Machado. São Paulo: Companhia das Letras, 2011.

MARIZ, Vasco. História da música no Brasil. 6 ed. ampl. e atual. Rio de Janeiro: Nova Fronteira, 2005. 
MARTINS, Mirian Celeste et al. Didática do ensino de arte: a língua do mundo: poetizar, fruir e conhecer arte. 1 ed. São Paulo: FTD, 1998.

MATTOS, Cleofe Person de. Inteligência musical. Rio de Janeiro, RJ. Tese apresentada a concurso para cadeira de Teoria Musical. UFRJ. 1958.

MORAES, José Geraldo Vinci de. História e música: canção popular e conhecimento histórico. Revista Brasileira de História. São Paulo: ANPUH, v. 20, n. 39, 2000. Disponível em: $\quad$ http://www.scielo.br/scielo.php?pid=S0102-01882000000100009\&script=sci_arttext. Acesso em: 21 mar. 2014.

PAZ, Ermelinda. Pedagogia musical brasileira no século XX: metodologias e tendências. 1 ed. Brasília: Musimed, 2000.

SCHAFER, Raymond Murray. $O$ ouvido pensante. Tradução: Marisa Trench de O. Fonterrada; Magda R. Gomes da Silva; Maria Lúcia Pascoal. São Paulo: UNESP, 1991.

SILVA, Tomaz Tadeu da (org). Alienígenas na sala de aula: uma introdução aos estudos culturais em educação. 5 ed. Petrópolis: Vozes, 2005.

SOUZA, Jussmara. Cultura e diversidade na América Latina: o lugar da educação musical. Revista da ABEM, Porto Alegre: ABEM, v. 18, 2007. Disponível em: http://abemeducacaomusical.org.br/Masters/revista18/revista18_artigo2.pdf. Acesso em: 21 mar. 2014.

SWANWICK, Keith. Permanecendo fiel à música na educação musical. In: ENCONTRO NACIONAL DA ABEM, 2, Porto Alegre, 1993. Anais. Porto Alegre, ABEM, 1993. 19-32.

ULHÔA, Martha Tupinamba de. Nova história, velhos sons: notas para ouvir e pensar a música brasileira popular. Debates. Rio de Janeiro: UNIRIO, v.1, n.1, 1997. Disponível em: http://www4.unirio.br/mpb/ulhoatextos/NovaHistoriaVelhosSons_Debates_2Jul.pdf. Acesso em: 03 jun. 2013. 